\title{
Paul Martini
}

Paul Martini wurde am 25 Januar 1889 in Frankenthal in der Pfalz geboren. Nach seiner Gymnasialzeit von 1898 bis 1907 in Landau, Frankenthal und Ludwigshafen studierte er Medizin in München und Kiel. 1917 promovierte er mit der Arbeit „Veränderungen des zentralen und peripheren Pulses unter verschiedenen Einflüssen“, die er im Institut von Otto Frank, München, anfertigte.

Danach war er erst Assistent, dann Oberarzt an der II. Medizinischen Klinik der Universität München und habilitierte sich dort bei Friedrich von Müller. Nachdem er 1926 zum außerordentlichen Professor ernannt worden war, übernahm er 1927 als Chefarzt die medizinische Leitung des St. Hedwigs-Krankenhauses in Berlin.

1932 veröffentlichte Paul Martini die erste Auflage seiner Monografie „Methodenlehre der Therapeutischen Untersuchung“. Für ihn bestand Handlungsbedarf angesichts der Vielzahl der medikamentösen Therapien, die damals ohne Prüfung und Zulassung auf den Markt kommen konnten. Auf 69 Seiten fasste Paul Martini seine Erfahrungen mit der wissenschaftlichen Untersuchung der Medikamentenwirksamkeit zusammen und plädierte dafür, die Überprüfung von Medikamenten nicht mehr rein subjektiven „klinischen Impressionen“ zu überlassen, sondern methodisch anzugehen. Als erster führte er den Begriff „klinische Pharmakologie“ ein und beschrieb die Grundzüge von klinischen Prüfungen, die auch heute noch Gültigkeit haben. Da in der Zeit des Nationalsozialismus deutsche Beiträge zur Wissenschaft auf internationaler Ebene wenig beachtet wurden, haben seine grundlegenden Vorschläge nicht die ihnen eigentlich zustehende Anerkennung gefunden.

Paul Martini wurde 1932 auf den Lehrstuhl für Innere Medizin der Universität Bonn berufen und setzte hier als Direktor der Medizinischen Klinik, die damals auch die Neurologie umfasste, seine therapeutischen Studien bis zu seiner Emeritierung 1957 fort. 1948 wurde er - auch aufgrund seines untadeligen Verhaltens während der Zeit des Nationalsozialismus - zum ersten Nachkriegspräsidenten der Deutschen Gesellschaft für Innere Medizin (DGIM) gewählt und leitete in Wies-

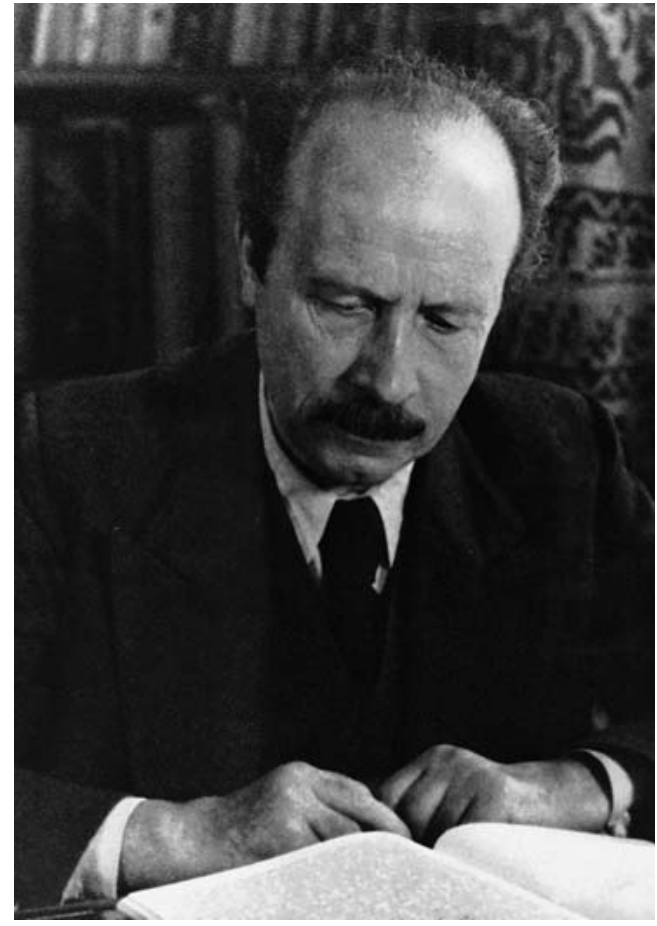

Paul Martini.

baden den ersten Internistenkongress nach dem 2. Weltkrieg.

In den Jahren 1952 und 1953 war er Rektor der Rheinischen Friedrich-Wilhelms-Universität Bonn.

1957 erhielt er die Paracelsus-Medaille, die höchste Auszeichnung der deutschen Ärzteschaft, 1959 wurde er in die Leopoldina aufgenommen und wurde Ehrenmitglied der DGIM.

Paul Martini, der zahlreiche weitere Ehrungen erhielt, verstarb am 8. September 1964 in Galenberg in der Eifel, wenige Tage nachdem er die 4. Auflage seiner Methodenlehre abgeschlossen hatte. Er wurde in der Nähe von Maria Laach begraben.

Mit der 1966 gegründeten Paul-Martini-Stiftung werden seine herausragenden Verdienste auf dem Gebiet der klinischen Pharmakologie gewürdigt und ihm ein ehrendes Andenken bewahrt. 10.1055/s-0042-117073

Drug Res 2016; 66, Suppl. 1: S3

(c) Georg Thieme Verlag KG

Stuttgart · New York .

ISSN 0004-4172

Korrespondenzadresse

Dr. Siegfried Throm

Geschäftsführendes

Vorstandsmitglied der

Paul-Martini-Stiftung

Hausvogteiplatz 13

10117 Berlin

s.throm@vfa.de 